Article

\title{
Simultaneous determination of the concentrations of isoproterenol, uric acid, and folic acid in solution using a novel nanostructure- based electrochemical sensor
}

\author{
Mohammad Mazloum-Ardakani a,*, Fariba Sabaghian a, Alireza Khoshroo a , Hossein Naeimi ${ }^{b}$ \\ a Department of Chemistry, Faculty of Science, Yazd University, Yazd, 89195-741, Iran \\ b Department of Organic Chemistry, Faculty of Chemistry, University of Kashan, Kashan, 87317, Iran
}

\section{A R T I C L E I N F O}

Article history:

Received 18 October 2013

Accepted 7 January 2014

Published 20 April 2014

Keywords:

Isoproterenol

Uric acid

Folic acid

Carbon nanotube

Modified electrode

Electrocatalysis

\begin{abstract}
A B S T R A C T
A carbon paste electrode modified with 2-((7-(2,5-dihydrobenzylideneamino)heptylimino)methyl) benzene-1,4-diol (DHB) and carbon nanotubes were used to simultaneously determine the concentrations of isoproterenol (IP), uric acid (UA), and folic acid (FA) in solution. First, cyclic voltammetry was used to investigate the redox properties of the modified electrode at various scan rates. Next, the mediated oxidation of IP at the modified electrode is described. At the optimum $\mathrm{pH}$ of 7.0, the oxidation of IP occurs at a potential about $90 \mathrm{mV}$ less than that of an unmodified carbon paste electrode. Based on the results of differential pulse voltammetry (DPV), the oxidation of IP showed a dynamic range between 10 and $6000 \mu \mathrm{mol} / \mathrm{L}$, and a detection limit of $1.24 \mu \mathrm{mol} / \mathrm{L}$. Finally, DPV was used to simultaneously determine the concentrations of IP, UA, and FA in solution at the modified electrode.
\end{abstract}

(C) 2014, Dalian Institute of Chemical Physics, Chinese Academy of Sciences. Published by Elsevier B.V. All rights reserved.

\section{Introduction}

Electrochemical sensors composed of modified electrodes have proven to be an inexpensive and simple analytical tool with remarkable detection sensitivity, reproducibility, and ease of miniaturization compared with other instrumental analysis methods [1-4]. They have been used in a wide range of important applications in clinical, industrial, environmental, and agricultural analyses $[1,5,6]$. The modification of electrodes with redox modifiers is an interesting field in analytical chemistry. Redox modifiers are electroactive compounds that effectively shuttle electrons between the analyte and the electrode. One of the most important effects of any modifier is the reduction of the overpotential required for electrochemical reaction, which enhances the sensitivity and selectivity of the method.
Because carbon nanotubes (CNTs) possess interesting electrochemical properties owing to the activity of edge-plane-like graphite sites at the CNT ends, they can be used to construct modified electrodes. These electrodes exhibit a low detection limit, high sensitivity, and fast response owing to the signal enhancement provided by the high surface area, low overvoltage, and rapid electrode kinetics $[7,8]$.

Isoproterenol (IP) is widely used for the treatment of primary pulmonary hypertension and allergic emergencies, status asthmaticus, bronchial asthma, ventricular bradycardia, cardiac arrest, and glaucoma [9]. It is also used to treat bronchitis, cardiac shock and heart attack. However, excess of the drug may cause heart failure and arrhythmias [10]. Several methods have been described to determine the concentration of IP in solution, such as spectrofluorometry, chemiluminescence [11], spectro-

\footnotetext{
* Corresponding author. Tel: +98-351-8211670; Fax: +98-351-8210644; E-mail: mazloum@yazd.ac.ir This work was supported by Yazd University Research Council, IUT Research Council and Excellence in Sensors. DOI: 10.1016/S1872-2067(14)60027-9 | http://www.sciencedirect.com/science/journal/18722067 | Chin. J. Catal., Vol. 35, No. 4, April 2014
} 
photometry [12], chromatography, and chemiluminescence methods. While these methods are often time consuming, inherently expensive, or complicated, electrochemical methods for the determination of the concentration of IP in solution have advantages such as simplicity, speed, low cost, and ease of use. Amperometric and voltammetric detection are inexpensive and sensitive techniques, and they have been widely used to detect electroactive compounds in pharmaceutical formulations, biological matrices, and medicinal herbs. Because IP contains hydroxyl groups on the aromatic ring and it has an $\mathrm{NH}$ group, it is electroactive, making it suitable for electrochemical detection [13-18].

Uric acid (UA) is a primary end product of purine metabolism. Abnormal levels of UA are an indicator of several diseases, such as gout, hyperpiesia, and Lesch-Nyhan syndrome [19]. Hence, monitoring the concentration of UA in biological fluids can be used as an early warning sign of these diseases. Colorimetric, enzymatic, and electrochemical methods are used to determine the concentration of UA $[20,21]$. The colorimetric method is unreliable for the accurate determination of the concentration of UA. Although determining the concentration of UA by enzymatic methods is promising because of their high level of selectivity, this methodology is inherently expensive and does not have a high detection limit. Electrochemical methods are more selective, less expensive, and less time-consuming than the other methods for determining the concentration of UA [22].

Folic acid (FA) is a water-soluble vitamin that acts as a coenzyme in the transfer and utilization of one-carbon groups and in the regeneration of methionine from homocysteine [23]. Deficiency of FA is a common cause of anemia and it is thought to increase the likelihood of heart attack and stroke. Many studies suggest that diminished folate status is associated with increased carcinogenesis because FA and vitamin B12 are involved in nucleotide synthesis, cell division, and gene expression [24]. Numerous methods for the measurement of FA are available, including enzyme-linked immunosorbent assays [22], liquid chromatography-tandem mass spectrometry [25], capillary electrophoresis [26], microemulsion electrokinetic chromatography [27], and high-performance liquid chromatography [28]. Because FA is an electroactive component, some electrochemical methods have been reported for its determination $[29,30]$. Compared with other methods, the electrochemical method is more desirable because of its convenience and low cost.

However, some studies have emphasized the instability of the attached materials on the electrodes as a problem in the use of chemically modified electrodes. It seems that the incorporation of electrocatalysts into the electrode matrix can, even partly, help to solve these problems, and carbon paste electrodes (CPEs) spiked with catalyst may be suitable for this purpose. The ease and speed of preparation for obtaining a new reproducible surface, the low residual current, the porous surface, and low cost are some advantages of chemically modified carbon paste electrodes [31-33].

In this study, we fabricated a novel nanostructure modified carbon paste electrode based on 2-((7-(2,5-dihydrobenzyli- deneamino)heptylimino)methyl)benzene-1,4-diol (DHB) and the unique properties of CNTs, and investigated its performance for the electrocatalytic determination of the concentration of IP in aqueous solution. We also evaluated the analytical performance of the modified electrode for quantification of IP in the presence of UA and FA. We found that DHB possesses high stability and good electrocatalytic activity toward the electrocatalytic oxidation of IP. In addition, we discuss the suitability of this modified electrode in the voltammetric determination of the concentration of IP in an aqueous solution by linear sweep voltammetry, differential pulse voltammetry, and chronoamperometry. Finally, the modified electrode was applied to determine the concentration of IP in blood samples.

\section{Experimental}

\subsection{Apparatus and chemicals}

The electrochemical measurements were performed with a potentiostat/galvanostat (SAMA 500, Iran). The experimental temperature was controlled at $25 \pm 1{ }^{\circ} \mathrm{C}$. A three-electrode cell was constructed, including a platinum wire, a saturated calomel electrode (SCE), and the modified electrode with modifier and nanoparticles (DHB/CNT/CPE) used as the auxiliary, reference, and working electrodes, respectively. A Metrohm $691 \mathrm{pH}$ meter was used to measure the $\mathrm{pH}$ of the solutions. IP, UA, FA, and all the other reagents were of analytical grade from Merck (Darmstadt, Germany). Graphite fine powder and paraffin oil (DC 350, density $=0.88 \mathrm{~g} / \mathrm{cm}^{3}$, Merck) were used as the binding agent to prepare the pastes. Buffer solutions were prepared from ortho-phosphoric acid and its salts in the $\mathrm{pH}$ range 4.0-9.0.

\subsection{Synthesis of $D H B$}

1,7-Diaminoheptane $(0.18 \mathrm{~g}, 1.4 \mathrm{mmol})$ was added to a mixture of 2,5-dihydroxybenzaldehyde $(0.35 \mathrm{~g}, 2.5 \mathrm{mmol})$ in methanol and stirring for $30 \mathrm{~min}$. The progress of the reaction was monitored by thin-layer chromatography. After the reaction was complete, the yellow solid product was filtered off and washed with cold methanol and pure Schiff base. 2,2'-[1,7Heptanediyl bis(nitrilomethylidene)]-bis(4-hydroxyphenol) was obtained in $90 \%$ yield $\left(\mathrm{mp}=215-217^{\circ} \mathrm{C}\right)$.

The Schiff base product was identified by physical and spectroscopic data as 2-((7-(2,5-dihydrobenzylideneamino)heptylimino)methyl)benzene-1,4-diol: yellow solid; yield 90\%; and mp 215-217 ${ }^{\circ} \mathrm{C}$. Anal. Calcd.: C 68.1, H 7.02, N 7.6; Found: C 68.1, H 6.9, N 7.4. IR (KBr, cm-1): v 3373-3500 (s, br, 2OH), 1646 (s, C=N), 1503, 1457 (Ar), 1239 (s, C-0). ${ }^{1} \mathrm{H}$ NMR (400 MHz/DMSO-d6): $\delta 12.7$ (br, 20H, intramolecular hydrogen bonding), 8.90 (br, 2OH), 8.42 (s, 2CH imine), 6.78 (d, 2H, Ar, J= $4 \mathrm{~Hz}$ ), 6.76 (dd, 2H, Ar, J1 = $8.2 \mathrm{~Hz}, J_{2}=2.2 \mathrm{~Hz}$ ), 6.69 (d, 2H, Ar, J $=8.4 \mathrm{~Hz}), 3.54\left(\mathrm{t}, 4 \mathrm{H}, 2 \mathrm{CH}_{2}, \mathrm{~J}=12.8 \mathrm{~Hz}\right), 1.58\left(\mathrm{~m}, 8 \mathrm{H}, 4 \mathrm{CH}_{2}\right), 1.33$ (m, 2H, $\mathrm{CH}_{2}$ ). ${ }^{13} \mathrm{C}$ NMR (100 MHz/DMSO-d6): $\delta 165.77,153.62$, 149.70, 120.12, 119.01, 117.25, 116.90, 59.02, 30.83, 28.88, 27.03. MS: $m / z=370\left(\mathrm{M}^{+}, 4\right), 235$ (6), 220 (22), 206 (28), 193 (90), 179 (32), 150 (68), 137 (92), 126(100). UV/ $\lambda_{\max } 340$ (s), $240(\mathrm{w})$. 


\subsection{Preparation of the electrode}

The DHB/CNT/CPE was prepared by hand mixing $0.01 \mathrm{~g}$ of DHB with $0.96 \mathrm{~g}$ graphite powder and $0.03 \mathrm{~g}$ nanoparticles with a mortar and pestle, Then, about $0.7 \mathrm{~mL}$ of paraffin was added to the above mixture and mixed for 20 min until a uniformly wetted paste was obtained. The paste was then packed into the end of a glass tube (ca. $3.7 \mathrm{~mm}$ i.d. and $10 \mathrm{~cm}$ long). A copper wire inserted into the carbon paste provided the electrical contact. When necessary, a new surface was obtained by pushing an excess of the paste out of the tube and polishing with a weighing paper. For comparison, a modified CPE (DHB/CPE) without CNTs, a CNT paste electrode (CNT/CPE) without DHB, and an unmodified CPE without both DHB and CNT were also prepared in the same way.

\section{Results and discussion}

\subsection{Electrochemical properties of modified DHP/CNT/CPE}

The DHB molecule is insoluble in aqueous solution and it can be incorporated into the carbon paste without leaching from the electrode surface. Therefore, the DHB/CNT/CPE was prepared and its electrochemical behavior was studied in aqueous solution by cyclic voltammetry (CV). One of advantage of this modified electrode is experimental reproducibility when the modification is carried out in a buffered solution at $\mathrm{pH} 7$. The results showed that over the $\mathrm{pH}$ range from 4 to 9 the slope $\left(E^{0^{\prime}} / \mathrm{pH}\right)$ was $47.0 \mathrm{mV}$, which is close to the predicted Nernstian value of $59.2 \mathrm{mV}$ for two electrons and two protons
[34].

At this modified electrode, when the potential was scanned from 0.05 to $0.35 \mathrm{~V}$ in phosphate buffer solution $(\mathrm{pH}=7.0)$ at a scan rate $(\mathrm{v})$ of $100 \mathrm{mV} / \mathrm{s}$, the anodic and cathodic peak potentials appeared at 0.283 and $0.182 \mathrm{~V}$ (vs $\mathrm{Ag} / \mathrm{AgCl} / \mathrm{KCl} 3.0$ mol/L), respectively, and $\Delta E_{\mathrm{p}}=0.101 \mathrm{~V}$ was greater than $(59 / n) \mathrm{mV}$ for a reversible system. The effect of the potential scan rate on the CV response of the DHB/CNT/CPE in the range 20-1600 mV/s is shown in Fig. 1(b). The plots of both the anodic and cathodic peak currents $\left(I_{\mathrm{p}}\right)$ are linearly dependent on the scan rate in this range. The linear relationship between the peak current and the scan rate indicates that the redox process is controlled in a diffusion-independent manner for the surface-confined redox process. Figure 1(d) shows the variations of the peak potentials $\left(E_{\mathrm{p}}\right)$ as a function of $\log v$. At scan rates above $90 \mathrm{mV}$, the peak potential values are proportional to $\log v$. Laviron derived the following expression [35] for the linear potential scan rate voltammetric response for the case of surface-confined electro active species with $E_{\mathrm{pa}}-E_{\mathrm{pc}}=\Delta E_{\mathrm{p}}>$ $200 / n \mathrm{mV}$ :

$$
\begin{gathered}
\log \left(k_{\mathrm{s}}\right)=\alpha \log (1-\alpha)+(1-\alpha) \log \alpha-\log (R T / n F v)- \\
\alpha(1-\alpha) n F \Delta E_{\mathrm{p}} / 2.3 R T
\end{gathered}
$$

where $k_{\mathrm{s}}$ is the apparent charge transfer rate constant and $\alpha$ is the transfer coefficient. The transfer coefficient can be determined from the slope of the plot of $E_{\mathrm{p}}$ against $\log t$. The plot of $E_{\mathrm{p}}=f(\log v)$ shows two straight lines with slopes equal to $2.3 R T / \alpha n F$ and $2.3 R T /(1-\alpha) n F$ for the cathodic and anodic peaks, respectively. These plots are shown in Fig. 1(d). Therefore the value of $\alpha$ was found to be 0.36 . Furthermore, from the values of $\Delta E_{\mathrm{p}}$ for different sweep rates and using Eq. (1), the
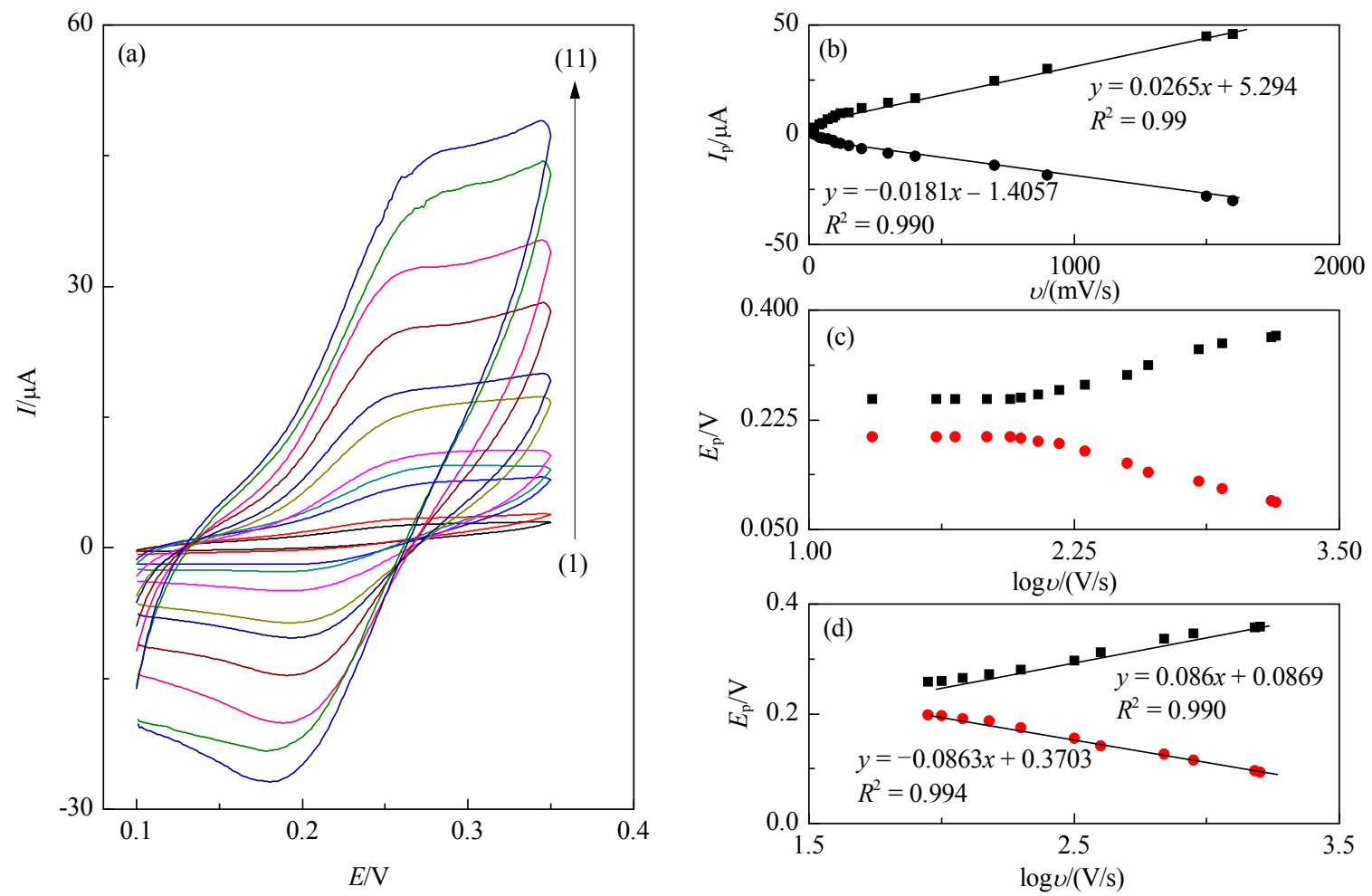

Fig. 1. (a) Cyclic voltammogram of the $\mathrm{DHB} / \mathrm{CNT} / \mathrm{CPE}$ in phosphate buffer solution $(0.1 \mathrm{~mol} / \mathrm{L}, \mathrm{pH}=7.0)$ at various scan rates $(v)$. The numbers (1)-(11) correspond to $v=20,40,100,120,150,300,400,700,900,1500$, and $1600 \mathrm{mV} / \mathrm{s}$. (b) Peak current $\left(I_{\mathrm{p}}\right)$ vs $v$. (c) Peak potential $\left(E_{\mathrm{p}}\right)$ vs $\log v$. (d) $E_{\mathrm{p}}$ vs $\log v$. 
average value of $k_{\mathrm{s}}$ was found to be $5.7 \mathrm{~s}^{-1}$.

An estimation of the surface coverage of the electrode, $\Gamma$, was made using the method of Sharp et al. [36]:

$$
I_{\mathrm{p}}=n^{2} F^{2} A \Gamma^{2} \mathrm{~V} / 4 R T
$$

where $n$ is the number of electrons involved in the reaction, $A$ is the surface area $\left(0.1 \mathrm{~cm}^{2}\right), \Gamma$ is $0.7 \times 10^{-9} \mathrm{~mol} / \mathrm{cm}^{2}$ for $n=2$, which for this electrode gives the optimum value of $\Gamma$. According to this method, the peak current is related to the surface concentration of the electroactive species.

\subsection{Electrocatalytic oxidation of IP at the DHB/CNT/CPE}

Figure 2 shows the CV response for the electrochemical oxidation of $0.5 \mathrm{mmol} / \mathrm{L}$ IP at the unmodified CPE, CNT/CPE, modified CPE at DHB, and DHB/CNT/CPE. In this figure, oxidation of IP at the surface of the unmodified CPE and CNT/CPE is about $360 \mathrm{mV}$, while oxidation of IP at the surface of the modified CPE at DHB and DHB/CNT/CPE is about $270 \mathrm{mV}$. These results indicate that the peak potential of IP oxidation at DHB/CNT/CPE decreased by about $90 \mathrm{mV}$ compared with the bare CPE, showing the electrocatalytic effect of the DHB/CNT/CPE for IP oxidation. Generally, CNTs increase the current compared with electrodes without CNTs, and the presence and absent of IP and modifier, respectively, lead to a decrease of the peak potential of IP oxidation compared with the electrode without modifier. In addition, the presence of IP leads to a decrease of the cathodic peak, which can be attributed to the strong electrocatalytic effect of the DHB/CNT/CPE for this compound [36]. According to Fig. 2, the best electrocatalytic effect for IP oxidation is at the DHB/CNT/CPE.

The effect of potential scan rate on the electrocatalytic oxidation of $0.5 \mathrm{mmol} / \mathrm{L} \mathrm{IP}$ at the DHB/CNT/CPE was investigated by cyclic voltammetry (Fig. 3(a)). The plot of peak current $\left(I_{\mathrm{p}}\right)$ versus the square root of scan rate $\left(v^{1 / 2}\right)$ is linear (Fig. 3(b)), suggesting that the IP electro-oxidation process is diffusion

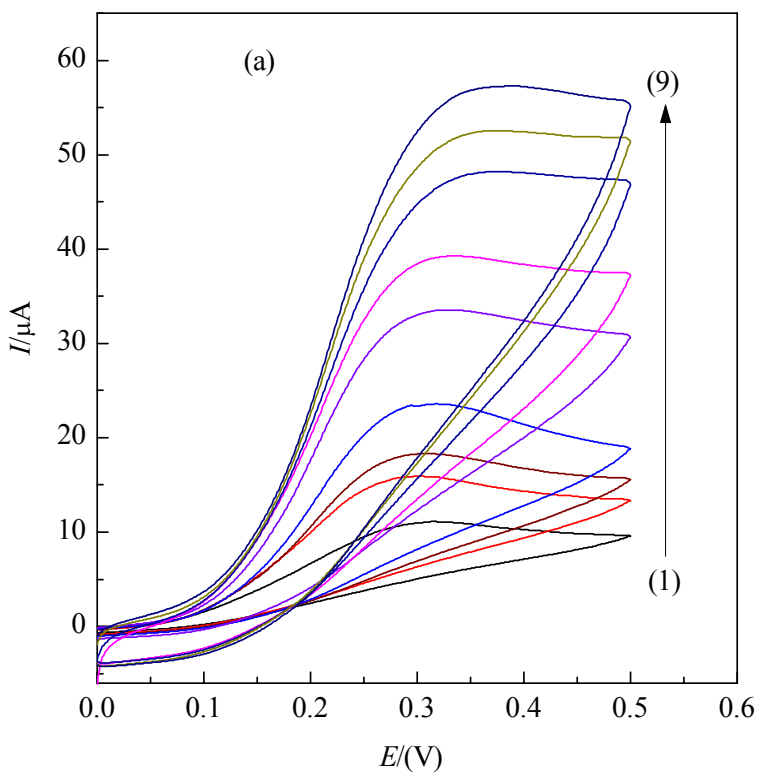

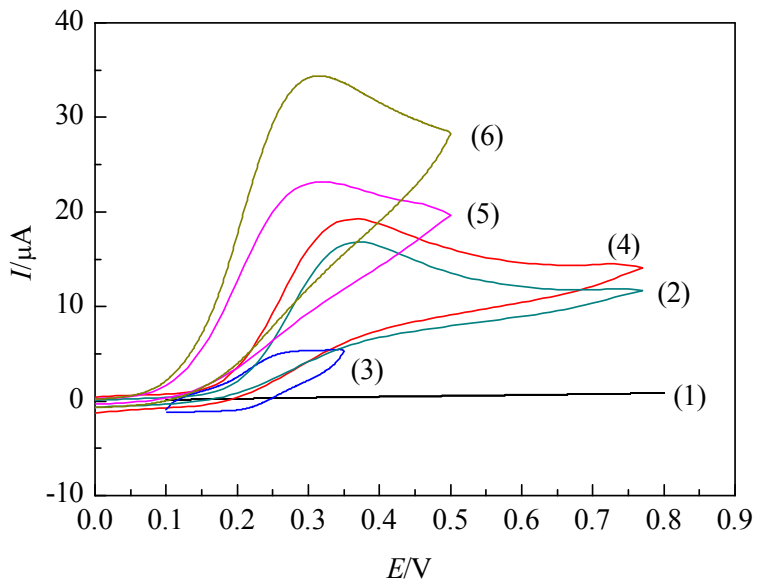

Fig. 2. Cyclic voltammetric response of (1) the unmodified CPE in phosphate buffer solution $(0.1 \mathrm{~mol} / \mathrm{L}, \mathrm{pH}=7.0)$ at a scan rate of 40 $\mathrm{mV} / \mathrm{s}$, (2) as with (1) but with $0.5 \mathrm{mmol} / \mathrm{L} \mathrm{IP,} \mathrm{(3)} \mathrm{as} \mathrm{with} \mathrm{(1)} \mathrm{but} \mathrm{at} \mathrm{the}$ surface of the DHB/CNT/CPE, (4) as with (2) but at the surface of the CNT/CPE, (5) as with (2) but at the surface of the DHB/CPE, and (6) as with (2) but at the surface of the DHB/CNT/CPE.

rather than surface controlled. A plot of the scan rate normalized current $\left(I_{p} / v^{1 / 2}\right)$ versus scan rate (Fig. 3(c)) shows the characteristic shape typical of an EC' electrocatalytic process [36].

The plot of the peak potential $\left(E_{\mathrm{p}}\right)$ versus the logarithm of current $(\log I)$ was constructed from the data of the increasing part of the current-voltage curve recorded at a scan rate of 25 $\mathrm{mV} / \mathrm{s}$ (Fig. 4). From the slope of the plot $(0.088 \mathrm{~V} /$ decade), and considering one electron transfer to be rate limiting $\left(n_{\alpha}=1\right)$, the transfer coefficient was obtained as $\alpha=0.64$.

\subsection{Chronoamperometric investigation}

Chronoamperometric measurements of IP at the DHB/CNT/
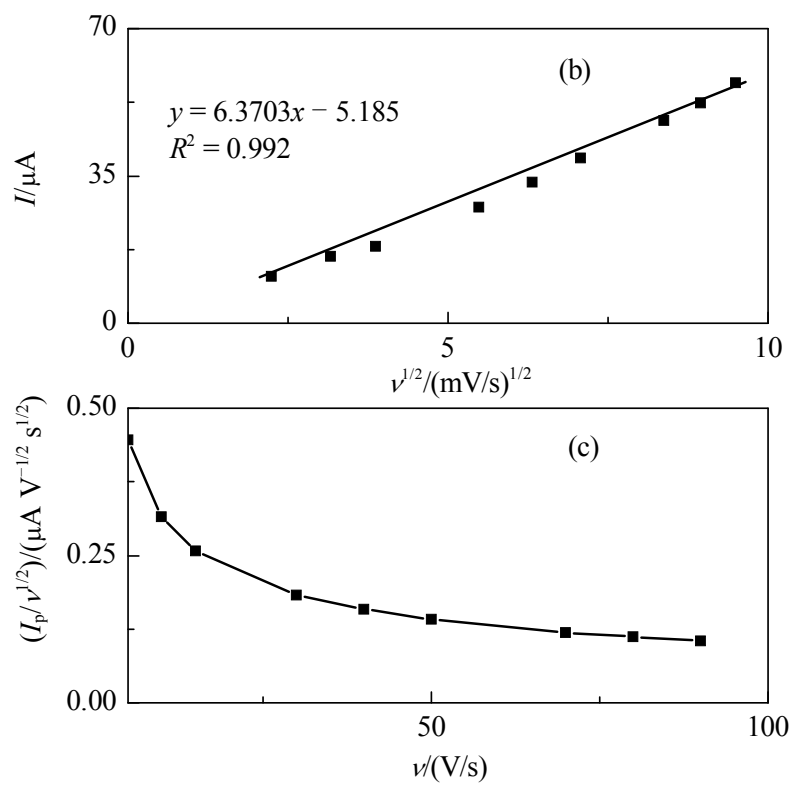

Fig. 3. (a) Cyclic voltammograms of DBH in phosphate buffer $(0.1 \mathrm{~mol} / \mathrm{L}, \mathrm{pH}=7.0)$ containing $0.5 \mathrm{mmol} / \mathrm{L}$ IP at different scan rates. The numbers (1)-(9) correspond to $5,10,15,30,40,50,70,80$, and $90 \mathrm{mV} / \mathrm{s}$ scan rates, respectively. (b) Variation of the electrocatalytic currents $\left(I_{\mathrm{p}}\right)$ vs the square root of scan rate $\left(v^{1 / 2}\right)$. (c) Variation of the scan rate normalized current $\left(I_{\mathrm{p}} / v^{1 / 2}\right)$ vs scan rate $(v)$. 


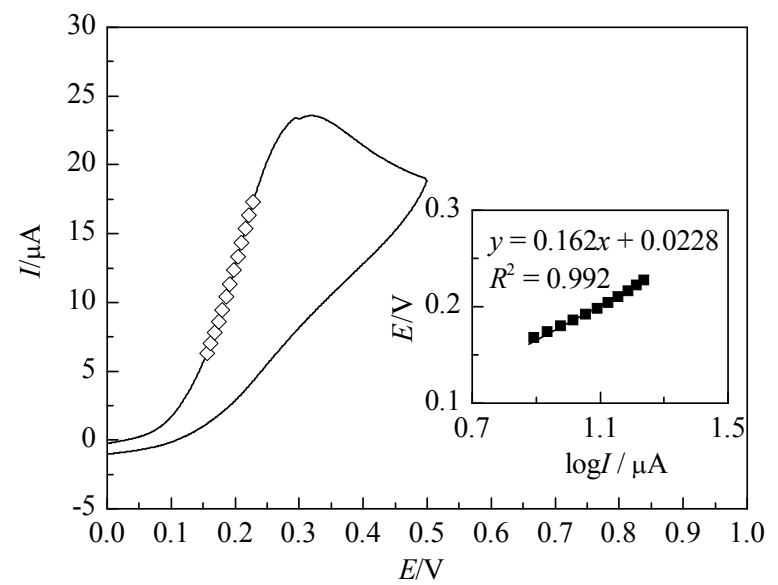

Fig. 4. Tafel plot derived from the increasing part of the cyclic voltammogram recorded at a scan rate of $25 \mathrm{mV} / \mathrm{s}$.

CPE were carried out at the working electrode potential of 350 $\mathrm{mV}$ for various concentrations of IP (Fig. 5(a)). For an electroactive material (IP in this case) with a diffusion coefficient of $D$, the current observed for the electrochemical reaction at the mass transport limited condition is described by the Cottrell equation [36]. Figure 5(b) shows the fitted experimental plots for different concentrations of IP. The slopes of the resulting
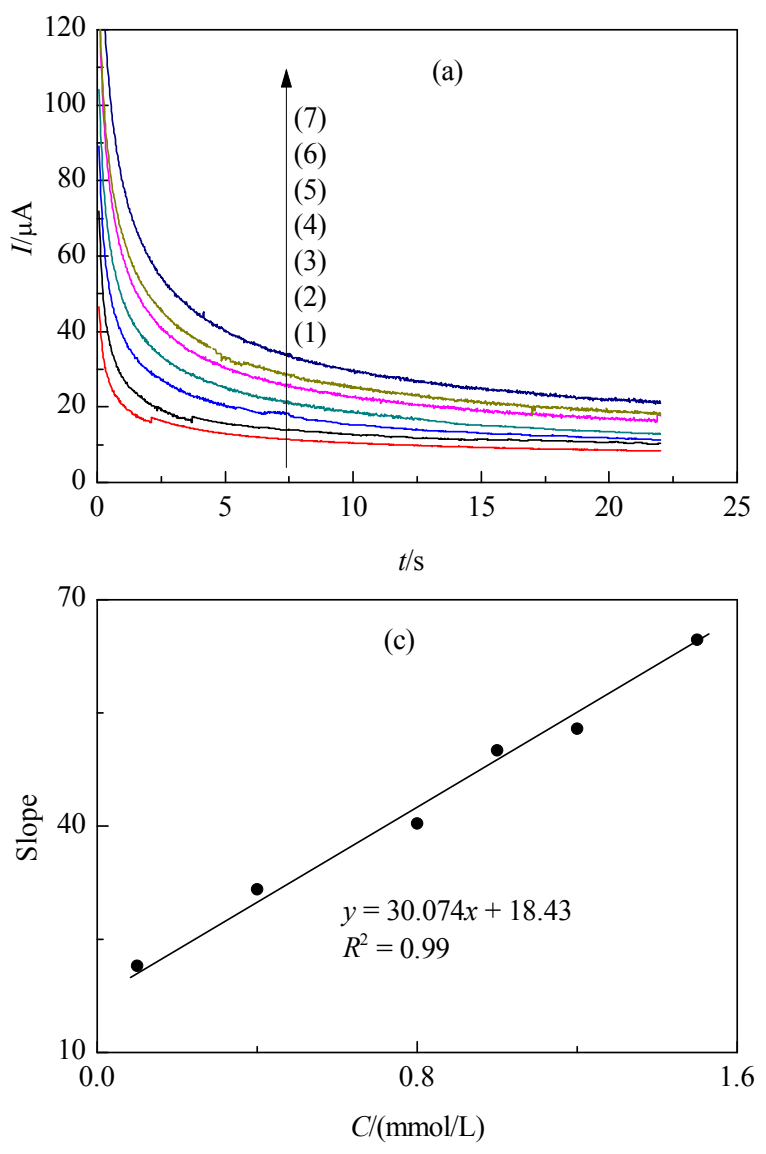

straight lines were then plotted against IP concentration (Fig. 5(c)). From the resulting slope and Cottrell equation, the mean value of the $D$ was found to be $7.84 \times 10^{-6} \mathrm{~cm}^{2} / \mathrm{s}$.

Chronoamperometry can also be used to evaluate the catalytic rate constant, $k$, for the reaction between IP and the DHB/CNT/CPE according to the method of Galus [37]:

$$
I_{C} / I_{L}=\gamma^{1 / 2}\left[\pi^{1 / 2} \operatorname{erf}\left(\gamma^{1 / 2}\right)+\exp (-\gamma) / \gamma^{1 / 2}\right]
$$

where $I_{C}$ is the catalytic current of IP at the DHB/CNT/CPE, $I_{\mathrm{L}}$ is the limited current in the absence of IP and $\gamma=k C_{\mathrm{b}} t$ is the argument of the error function $\left(C_{\mathrm{b}}\right.$ is the bulk concentration of IP). In cases where $\gamma>2$, the error function is almost equal to 1 , and, therefore, the above equation can be reduced to

$$
I_{\mathrm{C}} / I_{\mathrm{L}}=\pi^{1 / 2} \gamma^{1 / 2}=\pi^{1 / 2}\left(k C_{\mathrm{b}} t\right)^{1 / 2}
$$

where $t$ is the time elapsed. The above equation can be used to calculate $k$ of the catalytic process from the slope of $I_{C} / I_{L}$ vs. $t^{1 / 2}$ at a given IP concentration. From the values of the slopes, the average value of $k$ was found to be $4.5 \times 10^{-4} \mathrm{~L} /(\mathrm{mol} \cdot \mathrm{s})$.

\subsection{Calibration plot and limit of detection}

The electrocatalytic peak current of IP oxidation at the surface of the DHB/CNT/CPE can be used to determine the concentration of IP in solution. Differential pulse voltammetry (DPV) experiments were performed using the DHB/CNT/CPE
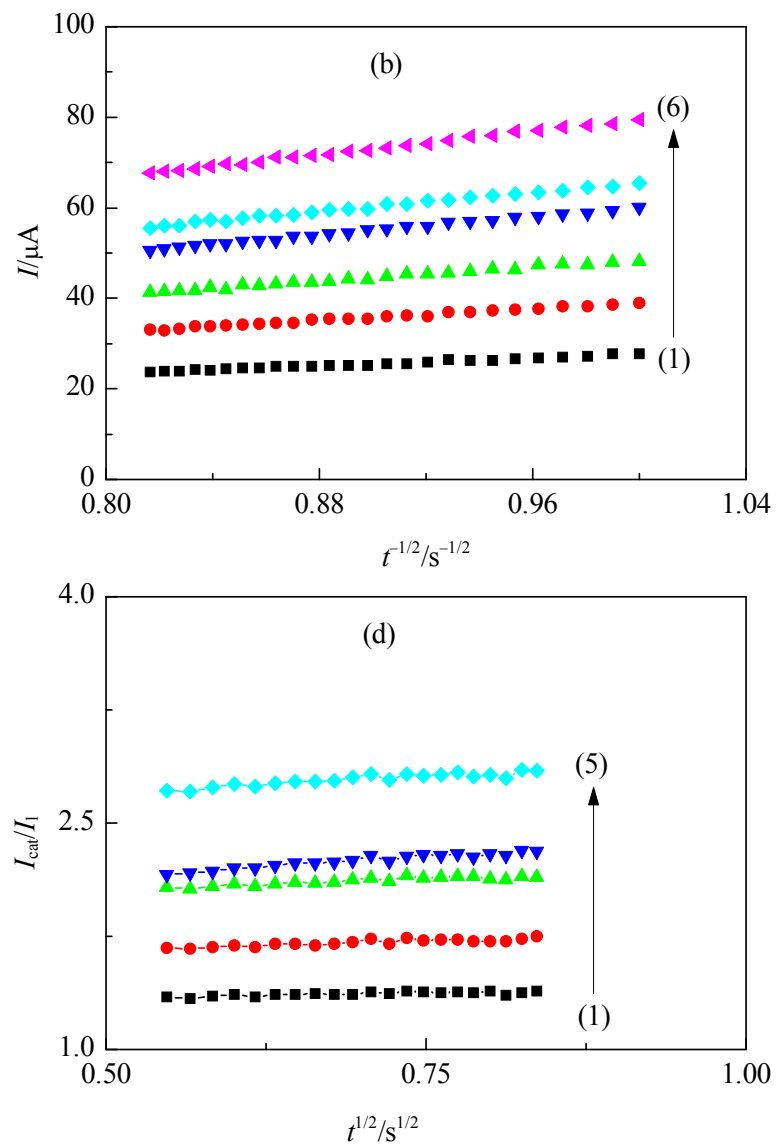

Fig. 5. (a) Chronoamperograms obtained at the DHB/CNT/CPE in phosphate buffer solution $(0.1 \mathrm{~mol} / \mathrm{L}, \mathrm{pH}=7.0)$ for different concentrations of IP. The numbers (1)-(7) correspond to $0,0.1,0.4,0.8,1,1.2$, and $1.5 \mathrm{mmol} / \mathrm{L}$ of IP, respectively. (b) Plots of $I$ vs $t^{-1 / 2}$ obtained from the chronoamperograms. (c) Plot of the slope of the straight lines against the IP concentration. (d) Dependence of $I_{\text {cat }} / I_{l}$ on $t^{1 / 2}$ derived from the data of the chronoamperograms. 
in phosphate buffer solutions containing various concentrations of IP. The plot of peak current vs. IP concentration consisted of two linear segments with slopes of 0.115 and $0.016 \mu \mathrm{A}$ $\mathrm{mol}^{-1} \mathrm{~L}$ in the concentration ranges of $10-100$ and $100-6000$ $\mu \mathrm{mol} / \mathrm{L}$, respectively. The main advantage of this work is that it can be compared with other studies is a very wide dynamic range (between 10 and $6000 \mu \mathrm{mol} / \mathrm{L}$ ) for IP determination (Table 1). The decrease in sensitivity (slope) in the second linear range is likely to be due to kinetic limitation. The detection limit $(3 \sigma)$ for IP in the lower range region was found to be 1.24 $\mu \mathrm{mol} / \mathrm{L}$.

\subsection{Simultaneous determination of $I P, U A$, and FA concentration}

The ability to resolve the electrochemical responses of different analytes is one of the important factors for choosing the type of modified electrode. The main objective of this study was to simultaneously determine the concentrations of IP, UA, and FA using the DHB/CNT/CPE. This was performed by simultaneously changing the concentrations of IP, UA, and FA, and recording the DPVs. The voltammetric results showed welldefined anodic peaks at potentials of $0.26,0.4$, and $0.74 \mathrm{~V}$, corresponding to the oxidation of IP, UA and FA, respectively, indicating that simultaneous determination of these compounds is feasible at the DHB/CNT/CPE, as shown in Fig. 6.

The sensitivity of the DHB/CNT/CPE towards IP in the absence $\left(0.115 \mu \mathrm{A} \mathrm{mol}^{-1} \mathrm{~L}\right)$ and presence $\left(0.119 \mu \mathrm{A} \mu \mathrm{mol}^{-1} \mathrm{~L}\right)$ of $\mathrm{UA}$ and FA are virtually the same, which further indicates that the oxidation processes of IP, UA, and FA at the DHB/CNT/CPE are independent, and, therefore, simultaneous determination of the three analytes is possible without any interference. The linear ranges (and detection limits) of UA and FA at the DHB/CNT/CPE were obtained as 125.0-2500.0 (5.3 $\mu \mathrm{mol} / \mathrm{L})$ and 75.0-1500.0 (6.97 $\mu \mathrm{mol} / \mathrm{L})$, respectively. Therefore, using the DHB/CNT/CPE is a useful, easy, and inexpensive way to simultaneously determine the concentrations of IP, UA, and FA. The detection limits and linear ranges are comparable with values reported by other research groups for electrocatalytic oxidation of IP at the surface of chemically modified electrodes using other mediators (Table 1) [17,38-42].

\subsection{Interference study}

The influence of various foreign species on the determina- tion of IP concentration was investigated. The tolerance limit was taken as the maximum concentration under the optimal condition $(\mathrm{pH}=7)$. Of the foreign substances which caused an approximately $5 \%$ relative error in the determination. Ascorbic acid, dopamine, piroxicam, penicillin sodium, $N$-acetyl and captopril at 10 times the concentration of IP, and epinephrine and levodopa at 5 times the concentration of IP did not interfere in the determination of the concentration of IP.

\subsection{Real sample analysis}

To evaluate the analytical applicability of the proposed method, it was applied to determine the concentrations of IP, UA, and FA in human blood serum samples. The original sample was found to be free of IP, UA, and FA. Therefore, different amounts of IP, UA, and FA were added to the sample and analyzed by the proposed method. The concentrations of the three species in real samples are given in Table 2. Satisfactory accuracy of the experimental results was found for IP, UA, and FA.

\subsection{Repeatability and stability of the $D H B / C N T / C P E$}

The electrode capability for the generation of a reproducible surface was examined by cyclic voltammetric data obtained in optimum pH solution from five separately prepared DHB/CNT/ CPE samples. The calculated relative standard deviation (RSD) for various parameters was used as the criteria for satisfactory surface reproducibility (1\%-4\%). This degree of reproducibility is virtually the same as that expected for the renewal of ordinary carbon paste surfaces. In addition, the long-term stability of the DHB/CNT/CPE was tested over a 3 week period. When the CVs were recorded after the modified electrode was stored in ambient atmosphere at room temperature, the peak potential for IP oxidation was unchanged and the current signals showed less than $2.2 \%$ decrease of the initial response. The antifouling properties of the modified electrode towards IP oxidation and its oxidation products were investigated by recording the cyclic voltammograms of the modified electrode before and after being in the presence of IP. Cyclic voltammograms were recorded in the presence of IP after having cycling the potential for 20 cycles at a scan rate $100 \mathrm{mV} / \mathrm{s}$. The peak potentials were unchanged and the currents decreased by less than $2.1 \%$. Therefore, at the surface of the DHB/CNT/CPE, not only does the sensitivity increase, but the fouling effect of the analyte and its oxidation product also decreases. However, we

Table 1

Comparison of some electrochemical procedures used to determine the concentration of IP with CPE electrode.

\begin{tabular}{|c|c|c|c|c|c|}
\hline Modifier & $\mathrm{pH}$ & $\begin{array}{c}\begin{array}{c}\text { Scan rate } \\
(\mathrm{mV} / \mathrm{s})\end{array} \\
\end{array}$ & $\begin{array}{c}\text { Detection limit } \\
(\mu \mathrm{mol} / \mathrm{L})\end{array}$ & $\begin{array}{c}\text { Dynamic range } \\
(\mu \mathrm{mol} / \mathrm{L})\end{array}$ & Ref. \\
\hline Molybdenum (VI) complex & 7.0 & 10 & 0.035 & $0.07-600.0$ & [17] \\
\hline Poly(1-methylpyrrole)-DNA & 4.0 & 50 & 0.016 & $2.0-50.0$ & [38] \\
\hline p-Chloranil & 10.5 & 10 & 0.0089 & $0.015-100.0$ & [39] \\
\hline Ferrocenemonocarboxylic acid & 5.0 & 20 & 0.2 & $0.5-50.0$ & [40] \\
\hline 2,7-Bis(ferrocenyl ethyl)fluoren-9-one & 7.0 & 10 & 0.026 & $0.08-700.0$ & [41] \\
\hline (E)-2-((2-chlorophenylimino)methyl)benzene-1,4-diol & 7.0 & - & 0.47 & $0.5-1000.0$ & {$[18]$} \\
\hline $\mathrm{N}$-(3,4-dihydroxyphenethyl)-3,5- dinitrobenzamide & 8.0 & - & 0.51 & $0.7-500$ & [42] \\
\hline 2-((7-(2,5-dihydrobenzylideneamino)heptylimino)methyl)benzene-1,4-diol & 7.0 & 25 & 1.24 & $10-6000$ & this work \\
\hline
\end{tabular}



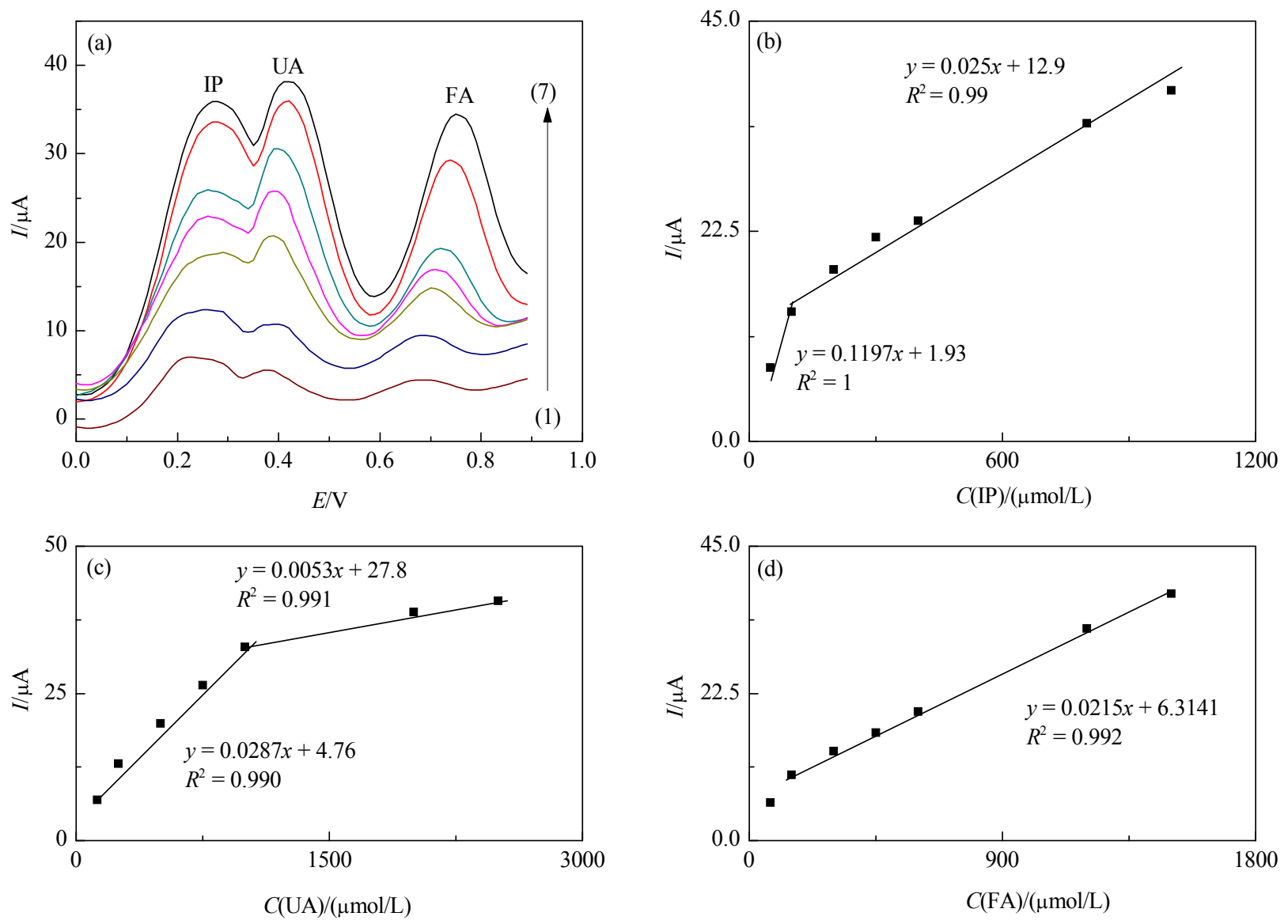

Fig. 6. (a) Differential pulse voltammograms of the DHB/CNT/CPE in phosphate buffer solution $(0.1 \mathrm{~mol} / \mathrm{L}, \mathrm{pH}=7.0)$ containing different concentrations of IP, UA, and FA from (1) to (7) ( $\mu \mathrm{mol} / \mathrm{L})$ : 50+125+75, 100+250+150, 200+500+300, 300+750+450, 400+1000+600, 800+2000+1200, and 1000+2500+1500. (b)-(d) Plot of the peak currents as a function of IP (b), UA (c) and FA (d) concentration.

Table 2

Determination of the concentration of IP, UA, and FA in serum samples.

\begin{tabular}{|c|c|c|c|c|c|c|c|c|c|}
\hline \multirow{2}{*}{ Sample } & \multicolumn{3}{|c|}{ Added $(\mu \mathrm{mol} / \mathrm{L})$} & \multicolumn{3}{|c|}{ Found $(\mu \mathrm{mol} / \mathrm{L})$} & \multicolumn{3}{|c|}{ Accuracy (\%) } \\
\hline & IP & UA & FA & IP & $\mathrm{UA}$ & FA & IP & UA & $\mathrm{FA}$ \\
\hline 1 & 600 & 1500 & 900 & 601.69 & 1497.32 & 901.25 & 100.28 & 99.82 & 100.14 \\
\hline 2 & 400 & 1000 & 600 & 404.03 & 1001.62 & 597.01 & 101 & 100.16 & 99.5 \\
\hline 3 & 300 & 750 & 450 & 294.21 & 748.99 & 451.0 & 98.07 & 99.86 & 98 \\
\hline 4 & 200 & 500 & 300 & 197.47 & 498.05 & 301.62 & 98.73 & 102.7 & 99.61 \\
\hline 5 & 100 & 250 & 150 & 102.01 & 253.83 & 150.65 & 102.01 & 101.53 & 100.43 \\
\hline 6 & 300 & - & 500 & 303.01 & - & 489.85 & 101 & - & 97.97 \\
\hline 7 & 300 & 500 & - & 299.21 & 501.95 & - & 99.73 & 100.39 & - \\
\hline
\end{tabular}

regenerated the surface of the DHB/CNT/CPE before each of the experiments in this study.

\section{Conclusions}

In this study, determination of the concentration of IP in solution was studied using a carbon paste electrode modified with DHB and CNTs, which leads to a decrease of the oxidation potential and an increase of the current. Cyclic voltammetry studies at different scan rates gave the cathodic and anodic transfer coefficients, which showed that the surface coverage of the electrode is very good. The detection limit was obtained from DPV investigation, and showed the lowest concentration of IP that could be measured. Simultaneous determination of the concentrations of IP, UA, and FA showed that complete resolution of the anodic wave was possible at potentials of 0.26 , 0.4 , and $0.74 \mathrm{mV}$, respectively. The advantages of this electrode include a wide linear range, good surface coverage of the electrode, and no interference in the determination of the concentration of IP. Furthermore, the high sensitivity, selectivity, and reproducibility of the voltammetric responses, together with the ease of preparation and surface regeneration, makes the proposed modified electrode very useful for accurate determination of the concentration of IP in real samples. 


\section{Graphical Abstract}

Chin. J. Catal., 2014, 35: 565-572 doi: 10.1016/S1872-2067(14)60027-9

Simultaneous determination of the concentrations of isoproterenol, uric acid, and folic acid in solution using a novel nanostructure-based electrochemical sensor

Mohammad Mazloum-Ardakani*, Fariba Sabaghian, Alireza Khoshroo, Hossein Naeimi

Yazd University, Iran; University of Kashan, Iran

A carbon paste electrode chemically modified with multiwall carbon nanotubes was prepared and used as a selective electrochemical sensor for the simultaneous determination of the concentrations of isoproterenol, uric acid and folic acid in solution.

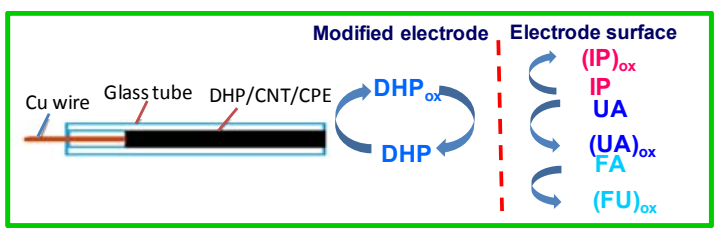

\section{References}

[1] Mazloum-Ardakani M, Sheikh-Mohseni M A, Abdollahi-Alibeik M, Benvidi A. Analyst, 2012, 137: 1950

[2] Chen X, Zhu J E, Xi Q, Yang W S. Sensor Actuat B, 2012, 161: 648

[3] Mazloum-Ardakani M, Taleat Z, Khoshroo A, Beitollahi H, Dehghani H. Biosens Bioelectron, 2012, 35: 75

[4] Mazloum-Ardakani M, Khoshroo A. Anal Chim Acta, 2013, 798: 25

[5] Justino C I L, Rocha-Santos T, Duarte A C, Rocha-Santos T A. Trends Anal Chem, 2010, 29: 1172

[6] Mazloum-Ardakani M, Sheikh-Mohseni M A, Benvidi A. Electroanalysis, 2011, 23: 2822

[7] Mazloum-Ardakani M, Sheikh-Mohseni M. In: Naraghi M Ed. Carbon Nanotubes - Growth and Applications. Rijeka: InTech, 2011. 395

[8] Yin S B, Zhu Q Q, Qiang Y H, Luo L. Chin J Catal (催化学报), 2012, 33: 290

[9] Goodman L S, Gilman A. The Pharmacological Basis of Therapeutics. 9th Ed. New York: McGraw-Hill, 1996

[10] Stryer L. Biochemistry. 3rd Ed. New York: Freeman, 1988

[11] Gamiz-Gracia L, Garcia-Campaña A M, Huertas-Perez J F, Lara F J. Anal Chim Acta, 2009, 640: 7

[12] Lupetti K O, Vieira I C, Fatibello-Filho O. Talanta, 2002, 57: 135

[13] Mazloum-Ardakani M, Naser-Sadrabadi A, Sheikh-Mohseni M A, Naeimi H, Benvidi A, Khoshroo A. J Electroanal Chem, 2013, 705: 75

[14] Bonifacio V G, Marcolino L H, Teixeira M F S, Fatibello-Filho O. Microchem J, 2004, 78: 55

[15] Ensafi A A, Dadkhah M, Karimi-Maleh H. Colloids Surf B, 2011, 84: 148

[16] Mashige F, Matsushima Y, Miyata C, Yamada R, Kanazawa H, Sakuma I, Takai N, Shinozuka N, Ohkubo A, Nakahara K. Biomed Chromatogr, 1995, 9: 221

[17] Kutluary A, Aslanoglu M. Acta Chim Slov, 2010, 57: 157

[18] Mazloum-Ardakani M, Hosseinzadeh L, Khoshroo A, Naeimi H, Moradian M. Electroanalysis, 2014, 26: 275

[19] Cunningham S K, Keaveny T V. Clin Chim Acta, 1978, 86: 217

[20] Mazloum-Ardakani M, Naser-Sadrabadi A, Sheikh-Mohseni M A, Benvidi A, Naeimi H, Karshenas A. Ionics, 2013, 19: 1663

[21] Baghbamidi S E, Beitollahi H, Mohammadi S Z, Tajik S, Soltani-
Nejad S, Soltani-Nejad V. Chin J Catal (催化学报), 2013, 34: 1869

[22] Hoegger D, Morier P, Vollet C, Heini D, Reymon F, Rossier J S. Anal Bioanal Chem, 2007, 387: 267

[23] Pfeiffer C M, Fazili Z, McCoy L, Zhang M, Gunter E W. Clin Chem, 2004, 50: 423

[24] Mi Y, Liu Y T, Feng S S. Biomaterials, 2011, 32: 4058

[25] Nelson B C, Sharpless K E, Sander L C. J Chromatogr A, 2006, 1135 : 203

[26] Zhao S L, Yuan H Y, Xie C, Xiao D. J Chromatogr A, 2006, 1107: 290

[27] Aurora-Prado M S, Silvaa C A, Tavares M F M, Altria K D. J Chromatogr A, 2004, 1051: 291

[28] de Quiros A R B, de Ron C C, Lopez-Hernandez J, Lage-Yusty M A.J Chromatogr A, 2004, 1032: 135

[29] Bandžuchova L, Šelešovska R, Navratil T, Chýlková J. Electrochim Acta, 2011, 56: 2411

[30] Weng J, Zhang Z W, Sun L P, Wang J A. Biosens Bioelectron, 2011, 26: 1847

[31] Prasad B B, Madhuri R, Tiwari M P, Sharma P S. Sens Actuators B, 2010, 146: 321

[32] Mazloum-Ardakani M, Khoshroo A. Electrochim Acta, 2013, 103: 77

[33] Keyvanfard M, Karimi-Maleh H, Alizad K. Chin J Catal (催化学报), 2013, 34: 1883

[34] Laviron E.J Electroanal Chem, 1979, 101: 19

[35] Sharp M, Petersson M, Edstrom K. J Electroanal Chem, 1979, 95: 123

[36] Bard A J, Faulkner L R. Electrochemical Methods: Fundamentals and Applications. 2nd Ed. New York: Wiley, 2001

[37] Galus Z. Fundamentals of Electrochemical Analysis. NewYork: Ellis Horwood, 1976

[38] Ghorbani-Bidkorbeh F, Shahrokhian S, Mohammadi A, Dinarvand R. Electrochim Acta, 2010, 55: 2752

[39] Ensafi A A, Maleh H K. Int J Electrochem Sci, 2010, 5: 1484

[40] Beitollahi H, Raoof J B, Karimi-Maleh H, Hosseinzadeh R. J Solid State Electrochem, 2012, 16: 1701

[41] Beitollahi H, Mohadesi A, Mohammadi S, Akbari A. Electrochim Acta, 2012, 68: 220

[42] Ensafi A A, Bahrami H, Karimi-Maleh H, Mallakpour S. Chin J Catal (催化学报), 2012, 33: 1919 